\title{
Relationship of anthropometric indices with rate pressure product, pulse pressure and mean arterial pressure among secondary adolescents of 12-17 years
}

\author{
Godfrey Katamba ${ }^{1 *}\left(\mathbb{0}\right.$, Abdul Musasizi $^{2}$, Mivule Abdul Kinene $^{3}$, Agnes Namaganda ${ }^{4}$ and Francis Muzaale 5
}

\begin{abstract}
Objectives: To determine the correlation between anthropometric indices and the selected hemodynamic parameters among secondary adolescents aged 12-17 years.

Results: Our findings showed weak positive correlation between generally body surface area, neck circumference and conicity index with the hemodynamic parameters (systolic blood pressure, diastolic blood pressure, resting pulse rate, mean arterial pressure, rate pressure product and pulse pressure). However, the ponderosity index, body mass index and waist hip ratio showed negative weak correlations with the hemodynamic parameters. There was a significant difference in pulse pressure among the BMI categories. All parameters showed significant $(p<0.05)$ differences across the categories of neck circumference and waist hip ratio. Generally, in multivariate regression analysis, anthropometric indices showed significant prediction of the hemodynamic parameters.
\end{abstract}

Keywords: Anthropometric indices, Rate pressure product, Pulse pressure, Mean arterial pressure

\section{Introduction}

The role of anthropometric measurements in estimation of adiposity is widely used in both research and clinical settings. The indices, such as; bod mas index (BMI), and the waist hip ratio (WHR) have been used commonly to define overweight and obesity status, across various age categories. Recently, more indices such as the conicity index $(\mathrm{CI})$; ponderosity index (PI); body surface are (BSA), and neck circumference $(\mathrm{NC})$, attracted great attention. Overweight and obesity is highly associated with a number of non-communicable diseases including cardiovascular disease, diabetes mellitus, cancers, arthritis, ovarian dysfunction and so forth. Globally, based on the world health organization

\footnotetext{
*Correspondence: cgmkats13@gmail.com

${ }^{1}$ Department of Physiology, College of Health, Medicine and Life

Sciences, King Ceasor University, Kampala, Uganda

Full list of author information is available at the end of the article
}

(WHO), the prevalence of obesity has tripled since 1975, as in 2016 only more than 1.9 billion adults of age 18 years and greater were overweight, of which 650 million were obese [1]. Obesity plays a very vital role in the development of cardiovascular disease (CVD) [2-4]. Several simple anthropometric parameters have been greatly associated with cardiovascular risk factors [5] and thus their relationship with hemodynamic parameters needs to be explored. The rate pressure product (RPP) also known as the cardiovascular product, is the measure of stress put on the cardiac muscle, based on the number or times it needs to contract per minute and the arterial blood pressure that is pumping against it [6]. It is a direct indication of the energy demand of the heart and thus good measure of energy consumption by the heart. Anthropometric indices such as WHR, waist circumference (WC), and BMI were found to be significantly correlated with RPP among health young adults [7, 8], and an important predictor of cardiovascular events [9]. The

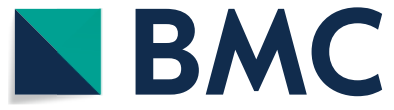

(c) The Author(s) 2021. This article is licensed under a Creative Commons Attribution 4.0 International License, which permits use, sharing, adaptation, distribution and reproduction in any medium or format, as long as you give appropriate credit to the original author(s) and the source, provide a link to the Creative Commons licence, and indicate if changes were made. The images or other third party material in this article are included in the article's Creative Commons licence, unless indicated otherwise in a credit line to the material. If material is not included in the article's Creative Commons licence and your intended use is not permitted by statutory regulation or exceeds the permitted use, you will need to obtain permission directly from the copyright holder. To view a copy of this licence, visit http://creativeco mmons.org/licenses/by/4.0/. The Creative Commons Public Domain Dedication waiver (http://creativecommons.org/publicdomain/ zero/1.0/) applies to the data made available in this article, unless otherwise stated in a credit line to the data. 
mean arterial pressure (MAP) is physiologically the average pressure in the arteries during a single cardiac cycle [10] and it is useful indicator of the pressure necessary for the adequate perfusion to vital organs. Additionally, the pulse pressure (PP) is an indirect marker of arterial stiffness and distensibility [11]. Both MAP and PP are important indicators of the pressure inside arteries and the extent of vasoconstriction or dilation. These have been found to be associated with anthropometric indices in elderly populations [12] and young adults elsewhere [13]. Further exploration of this relationship is needed for secondary school adolescents in Ugandan settings for a reliable comparison and better understanding of the cardiovascular related pathophysiology.

\section{Main text}

\section{Study design and data}

Data included in this study was part of a larger cross-sectional study which included up to 616 [14] adolescents aged 12-19 years in Mbarara municipality, southwestern Uganda. In this paper, only data of 485 participants aged 12-17 years was analyzed.

\section{Anthropometric measurements}

The methods were already described in detail by Katamba et al. [15]. Briefly, height (Ht) was measured using a wall mount height board without shoes in centimetres $(\mathrm{cm})$ [2]. Weight (Wt) was measured to the nearest $0.5 \mathrm{~kg}$ using a standard weighing scale (Seca 762, GmbH \& Co. KG, Hamburg, Germany) and participants were encouraged to put on light clothing with no items in the pockets and shoeless [3]. Waist circumference (WC) was measured by an inelastic flexible measuring tape with the participant standing while hip circumference (HC) at the level of the greater trochanter to the nearest $0.1 \mathrm{~cm}$ using an inelastic flexible measuring tape with the participant standing. Neck circumference (NC) was used as a surrogate measure for upper body adipose tissue distribution, measured at the level of the laryngeal prominence using an inelastic flexible measuring tape.

\section{Computations}

$$
\text { Ponderosity index }(\mathrm{PI})=\frac{\text { Weight in } \mathrm{kg}}{\text { Height in cubic meters }} \text { in } \frac{\mathrm{kg}}{\mathrm{m}^{3}}
$$

$$
\text { Body surface area (BSA) }=\sqrt{\frac{\text { Height }(\mathrm{cm}) x \text { weight }(\mathrm{kg})}{3600}} \text { in } \mathrm{m}^{2}
$$

based on the Mosteller formula [17]

$$
\text { Conicity index }(\mathrm{CI})=\frac{\text { waist circumference }(\mathrm{m})}{0.109 \sqrt{\frac{\text { weight }(\mathrm{kg})}{\text { height }(\mathrm{m})}}} \text { in } \mathrm{kgm}^{-3} \text {. }
$$

\section{Blood pressure and heart rate}

Blood pressure was measured using a digital blood pressure machine (Scian SP-582 Digital BP Monitor, Honsun, Jiangsu, China (Mainland) as already described by Katamba et al. [15]. Each participant was allowed to rest quietly for $5 \mathrm{~min}$, sitting on a chair with the back supported and feet on the floor [14]. The participant was asked to remain calm and quiet as the machine begun to measure automatically after pressing the start button. When the reading was complete, the monitor displayed the $\mathrm{BP}$ and the resting pulse rate on the digital panel [19]. Three readings were recorded per participant at 5 min' interval as recommend by the WHO steps surveillance guidelines for non-communicable diseases [20]. The average of the 2nd and 3rd respective $\mathrm{BP}$ measurements was used as the subject's BP, respectively. The rate pressure product (RPP) was computed as the product of systolic blood pressure and the resting pulse rate $(\mathrm{RPP}=\mathrm{SBP} \times \mathrm{RPR})$. Pulse pressure was the difference between systolic and diastolic blood pressure $(\mathrm{PP}=\mathrm{SBP}-\mathrm{DBP})$ while Mean arterial pressure $(\mathrm{MAP}=\mathrm{DBP}+1 / 3 \mathrm{PP})$.

\section{Statistical analysis}

The subjects were classified into different groups using anthropometric indices such as BMI, NC and WHR. The WHO 2007 BMI categories for age were used to classify adolescents into obesity categories [21]. Based on WHR, the subjects were classified into two groups, i.e., WHR $<0.90$ and $\mathrm{WHR} \geq 0.90$ (WHO cutoff points). The NC cut-offs for boys and girls were $30.75 \mathrm{~cm}$ and $29.75 \mathrm{~cm}$, respectively [22]. To compare two samples of a continuous variable, an unpaired t-test was used whereas for those with three categories, one-way ANOVA test was implemented. The anthropometric indices were tested for normality using the skewness and kurtosis test. The Pearson moment correlation coefficient was used to determine the correlations between anthropometric indices and the hemodynamic variables parameters followed by linear regression analysis. The anthropometric indices that showed a high variance inflation factor were removed from the final regression model to control for collinearity. $A p$ value $<0.05$ was considered to be statistically significant. The analysis of data was done by Stata software version 13.0 (College Station, Texas, USA). 


\section{Results}

\section{Physical characteristics of study participants by sex}

The mean age of the participants was $14.9 \pm 1.6$ years, the SBP and DBP of the participants were $111.9 \pm 8.9 \mathrm{mmHg}$ which differed significantly by sex and $65.0 \pm 7.4 \mathrm{mmHg}$, respectively. The mean resting pulse rate (RPR) was $75.0 \pm 8.1 \mathrm{bpm}$. The mean RPP was $84.1 \pm 12.8 \times 10^{2}$ mmHgbpm, while the mean PP was $46.9 \pm 7.9 \mathrm{mmHg}$ as showed in Table 1. A total of $6.6 \%(n=32)$ of the participants was obese based on the WHO 2007 BMI for age categories.

\section{Comparison of hemodynamic variables based on BMI categories}

Additional file 1: Table S1 shows the comparison hemodynamic parameters across the BMI categories. Data analysis was done by one-way ANOVA. There was a

Table 1 showing physical characteristics of the participants by compared by sex

\begin{tabular}{|c|c|c|c|c|}
\hline Variable & $\begin{array}{l}\text { Male } \\
(n=173) \\
\text { Mean } \pm S D\end{array}$ & $\begin{array}{l}\text { Female } \\
(n=312) \\
\text { Mean } \pm S D\end{array}$ & $\mathrm{p}$-value & $\begin{array}{l}\text { Total } \\
(n=485) \\
\text { Mean } \pm \text { SD }\end{array}$ \\
\hline 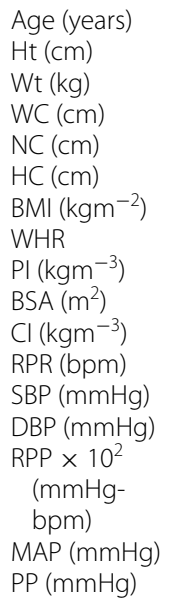 & $\begin{array}{l}14.5 \pm 1.5 \\
157.2 \pm 7.8 \\
55.0 \pm 7.3 \\
67.6 \pm 6.3 \\
29.7 \pm 2.5 \\
79.8 \pm 8.4 \\
22.3 \pm 2.9 \\
0.85 \pm 0.06 \\
14.2 \pm 2.2 \\
1.55 \pm 0.12 \\
1.05 \pm 0.09 \\
73.6 \pm 7.5 \\
109.6 \pm 10.9 \\
64.3 \pm 6.9 \\
80.8 \pm 11.9 \\
79.4 \pm 7.5 \\
45.3 \pm 8.6\end{array}$ & $\begin{array}{l}15.1 \pm 1.5 \\
156.9 \pm 7.4 \\
60.2 \pm 7.6 \\
69.9 \pm 6.9 \\
29.8 \pm 1.6 \\
93.3 \pm 11.1 \\
24.5 \pm 2.3 \\
0.75 \pm 0.06 \\
15.6 \pm 1.8 \\
1.6 \pm 0.13 \\
1.04 \pm 0.08 \\
75.8 \pm 8.4 \\
113.2 \pm 7.3 \\
65.4 \pm 7.6 \\
86.0 \pm 12.9 \\
81.3 \pm 6.6 \\
47.8 \pm 7.4\end{array}$ & $\begin{array}{l}<0.01 \\
0.620 \\
<0.01 \\
<0.01 \\
0.368 \\
<0.01 \\
<0.01 \\
<0.01 \\
<0.01 \\
<0.01 \\
0.072 \\
0.005 \\
<0.01 \\
0.123 \\
<0.01 \\
<0.01 \\
<0.01\end{array}$ & $\begin{array}{l}14.9 \pm 1.6 \\
156.9 \pm 7.6 \\
58.3 \pm 7.9 \\
69.1 \pm 6.8 \\
29.8 \pm 1.9 \\
88.5 \pm 12.1 \\
23.7 \pm 2.8 \\
0.79 \pm 0.08 \\
15.1 \pm 2.1 \\
1.6 \pm 0.13 \\
1.04 \pm 0.08 \\
75.0 \pm 8.1 \\
111.9 \pm 8.9 \\
65.0 \pm 7.4 \\
84.1 \pm 12.8 \\
80.6 \pm 6.9 \\
46.9 \pm 7.9\end{array}$ \\
\hline
\end{tabular}

$S D$ standard deviation significant difference in the cardiovascular parameters across ss all the BMI categories.

\section{Comparison of hemodynamic variables-based on neck circumference and waist hip ratio}

Additional file 1: Table S2 depicts the effect of NC and WHR on hemodynamic parameters. Comparison analysis was done using the unpaired $t$-test. The subjects of normal NC cm showed significant difference in all hemodynamic parameters with those of high $\mathrm{NC}(\mathrm{p}<0.01)$. The same significant differences were found between the WHR categories.

\section{Correlation analysis}

Correlation analysis of hemodynamic parameters with anthropometric indices was done as shown in Additional file 1: Table S3. Significant positive correlation coefficients were found between body surface area and neck circumference with RPP, MAP and PP. However, some negative coefficients were found for WHR and PI.

\section{Step wise regression analysis}

All anthropometric indices as shown in Table 2 were significantly associated with the cardiovascular parameters (RPP, MAP and PP) and this was controlled for sex. The multiple and stepwise regression analysis for of anthropometric indices in relation to hemodynamic parameters is shown in Table 3. BMI and WHR controlled for sex significantly predicted the rate pressure product (RPP) with explained variability of $7 \%$. This prediction improved after addition of conicity index in step $2\left(R^{2}=0.149\right)$. The explained variability in RPP later improved $\left(R^{2}=0.149\right.$ vs $0.169)$ after addition of the ponderosity index in step 3 of the analysis. The same improvement in the explained variability were observed for MAP and PP.

\section{Multiple linear regression equations for different stages of analysis}

Mean arterial pressure (MAP);

Table 2 Bivariate linear regression analysis of anthropometric indices with the cardiovascular parameters adjusted for sex

\begin{tabular}{|c|c|c|c|c|c|c|c|c|c|}
\hline \multirow[t]{2}{*}{ Variables } & \multicolumn{3}{|c|}{ Rate pressure product } & \multicolumn{3}{|c|}{ Mean arterial pressure } & \multicolumn{3}{|c|}{ Pulse pressure } \\
\hline & $\mathrm{R}^{2}$ & SEE & $\mathrm{F}$ & $\mathrm{R}^{2}$ & SEE & $\mathrm{F}$ & $\mathrm{R}^{2}$ & SEE & $\mathrm{F}$ \\
\hline BMI & 0.052 & 22.2 & $13.3^{*}$ & 0.021 & 0.1 & $5.1^{*}$ & 0.038 & 0.1 & $9.6^{*}$ \\
\hline WHR & 0.057 & 928.9 & $14.7^{*}$ & 0.056 & 5.1 & $14.4^{*}$ & 0.023 & 5.9 & $5.8^{*}$ \\
\hline $\mathrm{Cl}$ & 0.097 & 3407.9 & $25.9^{*}$ & 0.043 & 19.2 & $10.8^{*}$ & 0.031 & 22.0 & $7.6^{*}$ \\
\hline $\mathrm{Pl}$ & 0.077 & 28.7 & $20.0^{*}$ & 0.047 & 0.2 & $11.9^{*}$ & 0.025 & 0.2 & $6.2^{*}$ \\
\hline BSA & 0.066 & 446.9 & $16.9^{*}$ & 0.091 & 2.4 & $24.2^{*}$ & 0.082 & 2.8 & $21.6^{*}$ \\
\hline
\end{tabular}

SEE standard error of estimation, $R^{2}$ coefficient of determination, $F$ F-Statistic 
Table 3 Stepwise analysis showing changes in multiple regression coefficient of determination $\left(R^{2}\right)$ with addition of different anthropometric indices controlled for sex

\begin{tabular}{|c|c|c|c|c|c|c|c|c|c|}
\hline \multirow[t]{2}{*}{ Stages of analysis } & \multicolumn{3}{|c|}{ Rate pressure product } & \multicolumn{3}{|c|}{ Mean arterial pressure } & \multicolumn{3}{|c|}{ Pulse pressure } \\
\hline & $R^{2}$ & SEE & $\mathrm{F}$ & $R^{2}$ & SEE & $\mathrm{F}$ & $\overline{R^{2}}$ & SEE & $\mathrm{F}$ \\
\hline${ }^{1} \mathrm{BMI}$ and $\mathrm{WHR}$ & 0.072 & 21.9 & $12.4^{*}$ & 0.060 & 0.121 & $10.2^{*}$ & 0.038 & 0.139 & $6.4^{*}$ \\
\hline${ }^{2} \mathrm{BMI}, \mathrm{WHR}$ and $\mathrm{Cl}$ & 0.149 & 26.9 & $20.9^{*}$ & 0.117 & 0.150 & $15.9^{*}$ & 0.038 & 0.178 & $4.8^{*}$ \\
\hline${ }^{3} \mathrm{BMI}, \mathrm{WHR}, \mathrm{Cl}$ and $\mathrm{PI}$ & 0.169 & 59.1 & $19.5^{*}$ & 0.169 & 0.322 & $19.5^{*}$ & 0.084 & 0.386 & $8.8^{*}$ \\
\hline
\end{tabular}

SEE standard error of estimation, $R^{2}$ coefficient of determination, $F$ F-Statistic

${ }^{*} \mathrm{p}<0.05$

$$
\begin{aligned}
& { }^{1} M A P=102.4-0.17 B M I-22.8 W H R, \\
& { }^{2} M A P=75.3-0.35 B M I+136.8 C I-32.5 W H R, \\
& { }^{3} M A P=68.6+1.93 B M I-21.2 W H R-2.4 P I+108.6 C I .
\end{aligned}
$$

Pulse pressure (PP);

$$
\begin{aligned}
& { }^{1} P P=34.9+0.38 B M I+0.26 W H R, \\
& { }^{2} P P=37.0+0.34 B M I+W H R-10.6 C I, \\
& { }^{3} P P=29.9+2.0 B M I+13.1 W H R-2.5 P I-4.0 .8 C I .
\end{aligned}
$$

Rate pressure product (RPP);

$$
\begin{aligned}
& { }^{1} R P P=11505.8-59.7 B M I-2910 W H R, \\
& { }^{2} R P P=5713.7+51.0 B M I-4983 W H R+29172 C I, \\
& { }^{3} R P P=4944.5+232.5 B M I-3676.8 W H R-272.8 P I+25919.2 C I .
\end{aligned}
$$

\section{Discussion}

Our findings showed weak correlations between the anthropometric indices and the hemodynamic parameters. The correlations were all positive for $\mathrm{NC}$ and $\mathrm{CI}$. However, the PI, BMI and WHR showed negative weak correlations with the hemodynamic parameters. In regression analysis, combination of all anthropometric indices significantly predicted the hemodynamic parameters among our adolescents with improved explained variability. These observations carry physiological significance, as the increase in anthropometric indices results into increased stress on the cardiovascular system, as indicated by increase in hemodynamic parameters. Rate pressure product as marker of myocardial stress through surrogate indication myocardial oxygen consumption $\left(\mathrm{m} V \mathrm{O}_{2}\right)$ increased with increase in the anthropometric indices, as was also shown by pulse pressure, mean arterial pressure and blood pressure. Our findings are in agreement with those from a study that involved 104 male young adults aged $20-25$ years. The study found a positive correlation between anthropometric indices and rate pressure product [7]. Additionally, a study among primary pupils of 6-14 years found anthropometric indices such as height, weight, waist hip ratio to be significantly correlated with both blood pressure and pulse pressure [23]. The same findings were reported among secondary adolescents of 10-18 years in Gombe Nigeria [24]. Among the 397 apparently healthy men and women from Congolese in the south port city, waist circumference was found to be associated with pulse pressure and the strength of the associations varied with age, and blood pressure status [25]. In china, the simple anthropometric indices such as BMI, WC and WHR were found to be useful predictors for cardiovascular risk [5]. The same observations were reported among Brazilian adoles- cents [26] and in Korean women aged 40-69 years [27]. In the elderly population, it was found that higher values of anthropometric indices such as waist to height ratio and conicity index were closely related to increased diastolic BP, body fat and lipid profiles [28]. The same closely related findings were reported among the postmenopausal women in Tehran in Iran [29]. Neck circumference in children was found to show very comparable associations as those of BMI, WHR, WHtR and was closely associated cardiovascular disease risk factors among the 324 children aged 9-13 years in Greece [30].

\section{Conclusion}

A positive relationship between the anthropometric indices and hemodynamic parameters was found in general. All anthropometric indices combined predict the hemodynamic parameters better than a single index of adiposity.

\section{Limitations}

These include; (1) our results included only secondary school adolescents and hence may not be generalized across all adolescents in the general public, (2) the sample size was small to draw very valid conclusions and hence 
this calls for a larger national wide survey, (3) being a cross sectional study, no information on causality was obtained.

\begin{abstract}
Abbreviations
ANOVA: Analysis of variance; BMI: Body mass index; BP: Blood pressure; BSA: Body surface area; Cl: Conicity index; DBP: Diastolic blood pressure; HC: Hip circumference; Ht: Height; MAP: Mean arterial pressure; NC: Neck circumference; PI: Ponderosity index; PP: Pulse pressure; RPP: Rate pressure product; RPR: Resting pulse rate; SBP: Systolic blood pressure; SD: Standard deviation; SE: Standard error; WC: Waist circumference; WHO: World health organization WHR: Waist hip ratio; Wt: Weight.
\end{abstract}

\section{Supplementary Information}

The online version contains supplementary material available at https://doi. org/10.1186/s13104-021-05515-w.

Additional file 1: Table S1. Comparison of hemodynamic variables between Thinness, overweight and obese BMl subjects. Table S2.

Comparison of hemodynamic variables based on neck circumference and waist hip ratio categories. Table S3. Correlation between anthropometric indices and hemodynamic parameters.

\section{Acknowledgements}

We appreciate the contribution from the secondary schools and all the participants that participated in the study. We are thankful to all the study participants

\section{Authors' contributions}

GK: conceptualization of work and its realization, wrote the manuscript, checked the references, compiled the literature sources, data collection, statistical analysis, and interpretation of data, and wrote the manuscript and is the corresponding author. AN and FM: helped in the conceptualization of the work, helped in statistical and data analysis, support to data collection. AM and MAK: proof read the manuscript and searched for literature. All authors read and approved the final manuscript.

\section{Funding}

The study received no external funding.

\section{Availability of data and materials}

The dataset is available on request from the corresponding author.

\section{Declarations}

\section{Ethics approval and consent to participate}

This being part of larger cross-sectional story among secondary school adolescents of 12-19 years, the ethical issues were reported in detail by Katamba et al. [15]. Briefly, approval was obtained from the Mbarara university research ethics committee (IRB No. 18/03-18). The adolescents of 12-17 years (minors are considered anyone under 18 years according to Ugandan law) freely provided written assent, and their guardians (class teachers) provided written consent on their behalf.

\section{Consent for publication}

Not applicable.

\section{Competing interests}

The authors declare no conflict of interest.

\section{Author details}

'Department of Physiology, College of Health, Medicine and Life Sciences, King Ceasor University, Kampala, Uganda. ${ }^{2}$ Department of Biochemistry, College of Health, Medicine and Life Sciences, King Ceasor University, Kampala, Uganda. ${ }^{3}$ Department of Anatomy, College of Health, Medicine and Life
Sciences, King Ceasor University, Kampala, Uganda. ${ }^{4}$ Department of Physiology, Faculty of Health Sciences, Busitema University, Mbale, Uganda. ${ }^{5}$ Department of Physiology, Faculty of Health Sciences, Gulu University, Gulu, Uganda.

Received: 2 November 2020 Accepted: 5 March 2021

Published online: 17 March 2021

\section{References}

1. WHO. Obesity and overweight. 2020.

2. Fuchs FD, Gus M, Moreira LB, Moraes RS, Wiehe M, Pereira GM, Fuchs SC. Anthropometric indices and the incidence of hypertension: a comparative analysis. Obes Res. 2005;13(9):1515-7.

3. Ejtahed H-S, Qorbani M, Motlagh ME, Angoorani P, Hasani-Ranjbar S, Ziaodini H, Taheri M, Ahadi Z, Beshtar S, Aminaee TJE, et al. Association of anthropometric indices with continuous metabolic syndrome in children and adolescents: the CASPIAN-V study. Eat Weight Disord. 2018;23(5):597-604

4. Taing KY, Farkouh ME, Moineddin R, Tu JV, Prabhat P. Comparative associations between anthropometric and bioelectric impedance analysis derived adiposity measures with blood pressure and hypertension in India: a cross-sectional analysis. BMC Obes. 2017;4(1):37.

5. Ho S, Chen Y, Woo J, Leung S, Lam T, Janus EJ. Association between simple anthropometric indices and cardiovascular risk factors. Intern J Obes. 2001;25(11):1689-97.

6. Verma AK, Sun JL, Hernandez A, Teerlink JR, Schulte PJ, Ezekowitz J, Voors A, Starling R, Armstrong P, O'Conner CM. Rate pressure product and the components of heart rate and systolic blood pressure in hospitalized heart failure patients with preserved ejection fraction: Insights from ASCEND-HF. Clin Cardiol. 2018:41(7):945-52.

7. Jena S, Purohit K, Mohanty B. Correlation of anthropometric indices with rate pressure product in healthy young adults. Muller J Med Sci Res. 2017;8:82-5.

8. Mota J, Soares-Miranda L, Silva JME, Dos Santos SS, Vale SJ. Influence of body fat and level of physical activity on rate-pressure product at rest in preschool children. Am J Hum Biol. 2012;24(5):661-5.

9. Whitman M, Jenkins C, Sabapathy S, Adams LJH. Lung, circulation: rate pressure product versus age predicted maximum heart rate as predictors of cardiovascular events in intermediate risk patients during exercise stress echocardiography. Am J Cardiol. 2019;28:S315.

10. DeMers D, Wachs D. Physiology, mean arterial pressure. In: StatPearls [Internet]. edn.: StatPearls Publishing; 2019.

11. Homan TD, Cichowski E. Physiology, pulse pressure. In: StatPearls [Internet]. edn.: StatPearls Publishing; 2019.

12. Zhang J, Fang L, Qiu L, Huang L, Zhu W, Yu YJA. Comparison of the ability to identify arterial stiffness between two new anthropometric indices and classical obesity indices in Chinese adults. Atherosclerosis. 2017:263:263-71.

13. Staub K, Floris J, Koepke N, Trapp A, Nacht A, Maurer SS, Rühli FJ, Bender N. Associations between anthropometric indices, blood pressure and physical fitness performance in young Swiss men: a cross-sectional study. BMJ Open. 2018;8(6):e018664

14. Katamba G, Agaba DC, Migisha R, Namaganda A, Namayanja R, Turyakira E. Prevalence of hypertension in relation to anthropometric indices among secondary adolescents in Mbarara, Southwestern Uganda. Ital J Pediatr. 2020;46(1):76. https://doi.org/10.1186/s13052-020-00841-4.

15. Katamba G, Collins Agaba D, Migisha R, Namaganda A, Namayanja R, Turyakira E. Using blood pressure height index to define hypertension among secondary school adolescents in Southwestern Uganda. J Hum Hypertens. 2019. https://doi.org/10.1038/s41371-019-0292-x.

16. Urbina EM, Gidding SS, Bao W, Pickoff AS, Berdusis K, Berenson GSJC. Effect of body size, ponderosity, and blood pressure on left ventricular growth in children and young adults in the Bogalusa Heart Study. Circulation. 1995;91(9):2400-6

17. El Edelbi R, Lindemalm S, Eksborg SJ. Estimation of body surface area in various childhood ages — validation of the Mosteller formula. Acta Paediatr. 2012:101(5):540-4.

18. Fontela PC, Winkelmann ER, Viecili P. Study of conicity index, body mass index and waist circumference as predictors of coronary artery disease. Rev Port Cardiol. 2017;36(5):357-64. 
19. CDC (2018) High blood pressure during childhood and adolescence.

20. Ong SK, Lai DTC, Wong JYY, Si-Ramlee KA, Razak LA, Kassim N, Kamis Z, Koh D. Cross-sectional STEPwise approach to surveillance (STEPS) population survey of noncommunicable diseases (NCDs) and risk factors in Brunei Darussalam 2016. Asia Pac J Public Health. 2017;29(8):635-48.

21. Onis MD, Onyango AW, Borghi E, Siyam A, Nishida C, Siekmann J. Development of a WHO growth reference for school-aged children and adolescents. Bull World Health Organ. 2007;85:660-7.

22. Patnaik L, Pattnaik S, Rao EV, Sahu T. Validating neck circumference and waist circumference as anthropometric measures of overweight/obesity in adolescents. Indian Pediatr. 2017:54(5):377-80.

23. Abiodun AG, Egwu MO, Adedoyin RA. Anthropometric indices associated with variation in cardiovascular parameters among primary school pupils in ile-ife. Intern J Hypertens. 2011;2011:186194. https://doi.org/10.4061/ 2011/186194.

24. Wariri $\mathrm{O}$, Jalo I, Bode-Thomas F. Discriminative ability of adiposity measures for elevated blood pressure among adolescents in a resourceconstrained setting in northeast Nigeria: a cross-sectional analysis. BMC Obes. 2018;5(1):35. https://doi.org/10.1186/s40608-018-0211-7.

25. Bernard K, Evelyne M, Bernard K, Eleuthère K, Fiston MJ. Correlations between pulse pressure and anthropometric indices of obesity: crosssectional study in a Congolese Southwest Port City. J Heart Cardiovasc Res. 2017;1(1)

26. Kuciene R, Dulskiene $V$. Associations between body mass index, waist circumference, waist-to-height ratio, and high blood pressure among adolescents: a cross-sectional study. Sci Rep. 2019;9(1):9493. https://doi. org/10.1038/s41598-019-45956-9.

27. Lee J-W, Lim N-K, Baek T-H, Park S-H, Park H-Y. Anthropometric indices as predictors of hypertension among men and women aged 40-69 years in the Korean population: the Korean Genome and Epidemiology Study. BMC Public Health. 2015;15(1):140. https://doi.org/10.1186/ s12889-015-1471-5.

28. Milagres LC, Martinho KO, Milagres DC, Franco FS, Ribeiro AQ, Novaes JFD, Coletiva S. Waist-to-height ratio and the conicity index are associated to cardiometabolic risk factors in the elderly population. Cien Saude Colet. 2019:24:1451-61.

29. Shidfar F, Alborzi F, Salehi M, Nojomi M. Association of waist circumference, body mass index and conicity index with cardiovascular risk factors in postmenopausal women. Cardiovasc J Afr. 2012;23(8):442-5. https:// doi.org/10.5830/cvja-2012-038.

30. Androutsos $\mathrm{O}$, Grammatikaki $\mathrm{E}$, Moschonis G, Roma-Giannikou E, Chrousos G, Manios Y, Kanaka-Gantenbein CJ. Neck circumference: a useful screening tool of cardiovascular risk in children. Pediatr Obes. 2012;7(3):187-95.

\section{Publisher's Note}

Springer Nature remains neutral with regard to jurisdictional claims in published maps and institutional affiliations.
Ready to submit your research? Choose BMC and benefit from:

- fast, convenient online submission

- thorough peer review by experienced researchers in your field

- rapid publication on acceptance

- support for research data, including large and complex data types

- gold Open Access which fosters wider collaboration and increased citations

- maximum visibility for your research: over $100 \mathrm{M}$ website views per year

At BMC, research is always in progress.

Learn more biomedcentral.com/submissions 